\title{
Improved short term load forecasting of power system based on ARMA model
}

\author{
Weiheng Wang \\ Skill Training Center of Sichuan Electric Power Corporation Of State Grid, Chengdu, Sichuan \\ Province, China
}

\begin{abstract}
Keywords: ARMA model; improved recursive least square method; load forecasting; power system
\end{abstract}

Abstract: In this paper, the time series analysis method and the improved recursive least square parame-ter estimation method are used to realize the short-term forecasting of daily load and monthly load of elec-tric power system based on ARMA model. The method makes up for the shortage of weighted least square method, which guarantees the robustness and convergence speed of the algorithm. It has the characteristics of clear physical concept, small calculation amount and good numerical stability. Simulation results show that the algorithm has good prediction accuracy and can be satisfied with the results.

\section{Introduction}

Nowadays, with the rapid increase of the scale of power grid, the stability of the power grid is getting more and more attention. The load fluctuation of power system plays an important role in the stability of power system. Although the user has a certain law, but it is affected by climate change, price policy, equipment accident or overhaul, big holidays, social conditions, the occurrence of random events and other factors. The short-term load forecasting of electric power system, is ahead of a few hours to a few days and months to predict the load of the power system, can be used to determine the generation scheme of power plant, unit maintenance arrangements and guidance of economic operation, but also is the foundation to realize the real-time control and safety monitoring of power system (Gu, 2002).

The load fluctuation of power system can be divided into two kinds, which are deterministic and stochastic, and the power system load can be divided into two parts, the deterministic trend and random load. The trend part of the load is periodic, and the random part can be considered as a stationary sequence. The modeling and forecasting of the trend partial load are mainly adopted by polynomial and trigonometric function or neural network. ARMA model can be used to model and forecast the random part. There are three basic forms of ARMA model: Auto Regressive Model (AR), moving average model (MA) and mixed model (ARMA) (Luo, 2002).

In this paper, based on the ARMA model, the model is modified by the recursive least square method, and the short term load forecasting method of power system is established (Lin, 2006). The recursive least squares method for state estimation method is to estimate the data as the initial value of next time estimation by using a moment ago based on the more able to reflect the dynamics of the power system, is conducive to the power system of tracking. This method overcomes the shortcoming of using weighted least squares method, providing a more reliable initial value, the data is not in the process of calculation deviation from the true value, helps to ensure convergence, robustness and convergence speed of the algorithm, has a clear physical conception and a small amount of calculation and good numerical stability. Simulation results show that the algorithm has good prediction accuracy and can be satisfied with the results.

\section{Arma Model Description}

\subsection{AR model}

AR model is also known as self-regression model. It is through the prediction of observations in the 
past and present value of the linear combination of the interference prediction, since the mathematical formula for the regression model:

$$
y_{t}=\phi_{1} y_{t-1}+\phi_{2} y_{t-2}+\cdots+\phi_{p} y_{t-p}+\varepsilon_{t}
$$

Where: is the order of autoregressive model $(\mathrm{i}=1,2, \ldots, \mathrm{p})$ as a model of the undetermined coefficient (from regression coefficients) for the error, for a stationary time series. Which are independent and identically distributed random variables, and satisfy:

$$
E\left(\varepsilon_{t}\right)=0, \operatorname{Var}\left(\varepsilon_{t}\right)=\sigma_{\varepsilon}^{2}>0
$$

$\left\{y_{t}\right\}$ Called time series Subject to p-order autoregressive model. Also can be described a $\phi(B) y_{t}=y_{t-k}$.

If after the shift operator defined as B, namely:

Stationary conditions: lag operator polynomial $\phi(B)=1-\phi_{1} B+\ldots+\phi_{p} B^{p}$ roots are outside the unit circle, that $\phi(B)=0$ roots greater than $1(\mathrm{Lin}, 2006)$. $\mathrm{By}_{\mathrm{t}}=\mathrm{y}_{\mathrm{t}-1} \quad \mathrm{~B}_{\mathrm{k}} \mathrm{y}_{\mathrm{t}}=\mathrm{Y}_{\mathrm{t}-\mathrm{k}}$ the original type can be expressed as:

$$
y_{t}=\left(\phi_{1} B_{1}+\phi_{2} B_{2}+\cdots+\phi_{p} B_{p}\right) y_{t}+e_{t}
$$

\subsection{MA model}

MA model is also known as the moving average model. It is through the forecast value of the interference of the past and present value of the linear combination of the interference prediction. Moving average model mathematical formula is:

$$
\begin{aligned}
& y_{t}=\varepsilon_{t}-\phi_{1} \varepsilon_{t-1}-\phi_{2} \varepsilon_{t-2}-\cdots-\phi_{q} \varepsilon_{t-q} \\
& =\left(1-w_{1} B_{1}-W_{2} B_{2}-\cdots-W_{q} B_{q}\right) e_{t}
\end{aligned}
$$

Stationary conditions: stable under any circumstances.

Where: the order of the model; $(j=1,2, \cdots, q)$ is the coefficients for the model; is the error; is stationary time series. Which, $\mathrm{w}_{\mathrm{j}}(\mathrm{j}=1,2, \cdots, \mathrm{q})$ is the coefficients of model, $e_{t}$ is a zero mean disturbance term variance is not zero.

\subsection{ARMA models:}

Autoregressive models and moving average model portfolio constitute a stationary random process used to describe the autoregressive moving average model ARMA, mathematical formula is:

$$
\begin{aligned}
& y_{t}=\phi_{1} y_{t-1}+\phi_{2} y_{t-2}+\cdots+\phi_{p} y_{t-p}+\varepsilon_{t}-\theta_{1} \varepsilon_{t-1}- \\
& \theta_{2} \varepsilon_{t-2}-\cdots-\theta_{q} \varepsilon_{t-q}
\end{aligned}
$$

Then:

$$
\psi_{p}(B) y_{t}=W_{q} e_{t}
$$

Which:

$$
\begin{aligned}
& \psi_{p}(B)=1-\phi_{1} B-\phi_{2} B-\cdots-\phi_{p} B_{p} \\
& W_{q}(B)=1-W_{1} B-W_{2} B-\cdots W_{q} B_{q}
\end{aligned}
$$

Specially: $\mathrm{q}=0$, model is the $\operatorname{AR}(\mathrm{p}), \mathrm{p}=0$, model is the $\mathrm{MA}(\mathrm{q})$.

$e_{t}$ is zero mean white noise variance is not zero, $\Phi_{\mathrm{i}}(\mathrm{i}=1,2, \cdots, \mathrm{p})$ and $W_{\mathrm{j}}(\mathrm{j}=1,2, \cdots, \mathrm{q})$ is the coefficients of the model. It should be noted that the power system load change is a non-stationary random process, it has a certain growth trends and cyclical, in order ARMA model can be used to describe, it should define a difference operator (Yang, 2002).

$\delta=1-\mathrm{B}$, the $\delta \mathrm{y}_{\mathrm{t}}=\mathrm{y}_{\mathrm{t}}-\mathrm{y}_{\mathrm{t}}-1, \quad \delta^{\mathrm{m}}=(1-\mathrm{B})^{\mathrm{m}}$. This makes a trend of time series $\mathrm{y}_{\mathrm{t}}$, is transformed into stationary time series. ARMA model that can be used to describe the sequence of the. So get the following ARMA model:

$$
\psi_{p}(B) \delta^{m} y_{t}=W_{q}(B) e_{t}
$$

If the definition of periodic difference operators

$\Gamma_{s}=1-B^{s}$, then $\Gamma_{s} y_{t}=y_{t}-y_{t-s}, \quad \Gamma_{s} m=\left(1-B^{s}\right) m$ 
Therefore, the use of difference operators can handle the cyclical nature of the sequence, making periodic random sequence $\mathrm{y}_{\mathrm{t}}$ time series for a smooth transformation. Based on the above analysis, power system load forecasting ARMA model:

$$
\psi_{p}(B) \delta^{m} \Gamma^{m} y_{t}=W_{q}(B) e_{t}
$$

\section{Arma Model Parameters Identification T}

Identification of ARMA model parameters, including the identification and the order of the estimated model parameters.

\subsection{Determination of model order}

Time series $\mathrm{y}_{\mathrm{t}}(\mathrm{t}=1,2, \ldots \mathrm{N})$, The statistical analysis is as follows:

Mean:

$$
\mu_{y}=\frac{1}{N} \sum_{t=1}^{N} y_{t}
$$

Variance:

$$
\operatorname{Var}\left(y_{t}\right)=\sigma^{2} y=\frac{1}{N} \sum_{t=1}^{N}\left(y_{t}-\mu y\right)^{2}
$$

Covariance:

$$
\operatorname{Cov}\left(y_{t}, y_{t+k}\right)=\frac{1}{N-k}\left(y_{t}-\mu y\right)\left(y_{t+k}-\mu y\right)
$$

Autocorrelation function:

$$
\rho_{k}=\frac{\operatorname{Cov}\left(y_{t}-y_{t+k}\right)}{\sigma^{2} y}=\frac{\sum_{t=1}^{n-k}\left(y_{t}-\bar{y}\right)\left(y_{t+k}-\bar{y}\right)}{\sum_{t=1}^{n}\left(y_{t}-\bar{y}\right)^{2}}
$$

The $\bar{y}=\sum_{t=1}^{n} y_{t} / n$, It may indicate the different periods of the correlation between the data and its value in the range -1 to 1 , the value closer to 1 , indicating the time the higher the degree of autocorrelation.

Partial correlation function:

$$
\left\{\begin{aligned}
\Phi_{11} & =\rho_{1} \\
\Phi_{k k} & =\frac{\rho_{k}-\sum_{i-1}^{k-1} \Phi_{k-1, i} \rho_{k-1}}{1-\sum_{i-1}^{k-1} \Phi_{k-1, i} \rho_{i}}(\mathrm{k}=2,3, \ldots) \\
\Phi_{k, i} & =\Phi_{k-1, i}-\Phi_{k k} \Phi_{k-1, k-i} \quad(\mathrm{i}=1,2, \ldots, \mathrm{k}-1)
\end{aligned}\right.
$$

Therefore, the order of the model variables by testing the autocorrelation function and partial autocorrelation function to determine. For the AR model, the partial correlation function $\Phi_{k k}$ is censored. For the P-order AR model, the partial correlation function $\Phi_{k k}=0(\mathrm{k}>\mathrm{p})$. So when calculated $\Phi_{k k}=0$, you can determine the order of the model as $\mathrm{P}=\mathrm{k}-1$.

For the MA model, autocorrelation function $\rho_{\mathrm{k}}$ is censored. For the q-order MA model, and its autocorrelation function $\rho_{\mathrm{k}}=0(\mathrm{k}>\mathrm{q})$. So if obtained $\rho_{\mathrm{k}}=0$, it can determine the order of the model is $\mathrm{q}=\mathrm{k}-1$.

\subsection{The estimated model parameters}

Since the operation state of the power system is dynamic, only the time interval is short enough to be regarded as static. If the power system can track slow changes by the state variables of a period of time as the initial sampling period to estimate the state variables of a value, to ensure the stability 
of the initial value, its effect is better than static estimation, called tracking estimation method. The method is based on the least square estimation of the two time period before and after the system, which can be written as the objective function:

$$
L_{1}\left(x_{i}\right)=\left[x_{i}-x_{i-1}^{\prime}\right]^{T} P_{i-1}^{-1}\left[x_{i}-x_{i-1}^{\prime}\right]
$$

Among them, the $P_{i-1}$ is the variance matrix of the $i-1$ estimate of the state variable $x$, and its inverse matrix is used as the weight. $i$ measure of $Z_{i}$ and its corresponding stubborn $h\left(x_{i}\right)$ of the least square objective function:

$$
L_{2}\left(x_{i}\right)=\left[h\left(x_{i}\right)-z_{i}\right]^{T} R^{-1}\left[h\left(x_{i}\right)-z_{T}\right]
$$

The above can be written as the total objective function:

$$
L\left(x_{i}\right)=L_{1}\left(x_{i}\right)+L_{2}\left(x_{i}\right)
$$

The first Time recursive valuation should satisfy the conditions of $\frac{d L\left(x_{i}\right)}{d x_{i}}=0$ :

$$
h\left(x_{i}\right)=h\left(x_{i-1}^{\prime}\right)+H\left(x_{i-1}^{\prime}\right) \Delta x_{i}
$$

And

$$
\begin{aligned}
& x_{i}^{\prime}=x_{i-1}^{\prime}+P_{i} H\left(x_{i-1}^{\prime}\right)^{T} R^{-1}\left[z_{i}-h\left(x_{i-1}^{\prime}\right)\right] \\
& P_{i}=\left[P_{i-1}^{-1}+H\left(x_{i-1}\right)^{T} R^{-1} H\left(x_{i-1}^{\prime}\right)\right]^{-1}
\end{aligned}
$$

By using the matrix inversion lemma, the recursive formula is processed in some form, so that it can be the same as that of the conventional dynamic random sequence:

$$
\left\{\begin{array}{l}
x_{i}^{\prime}=x_{i-1}^{\prime}+K_{i}\left[z_{i}-h\left(x_{i-1}^{\prime}\right)\right] \\
K_{i}=P_{i-1} H^{T}\left[R+H P_{i-1} H^{T}\right]^{-1} \\
P_{i}=P_{i-1}-K_{i} H P_{i-1}
\end{array}\right.
$$

Formula (23) is the calculation formula of the least square recursive estimation of power system, which is called the recursive least square estimation. The idea of recursive algorithm is to obtain a new data, according to the new data on the original estimate to be modified, the new estimator is improved, rather than the new data to the old data inside the re calculation. The recursive state estimation can obtain the correct estimate of the state variable without a priori knowledge. The recursive state estimation is to use the estimated value of the previous moment as the initial value of the last time, and to improve the reliability and stability of the initial value in the state estimation. In normal operation, the running state of each moment is relatively stable, network load, parameters of small fluctuation, state estimation algorithm for fast convergence, very favorable for the detection and identification of bad data, reduce the detection and identification of time.

\section{Arma Model For Power System Load Forecasting}

\subsection{Determination of model order}

Daily load forecasting results, An area of SiChuan Province's 2014 Annual load curve: 


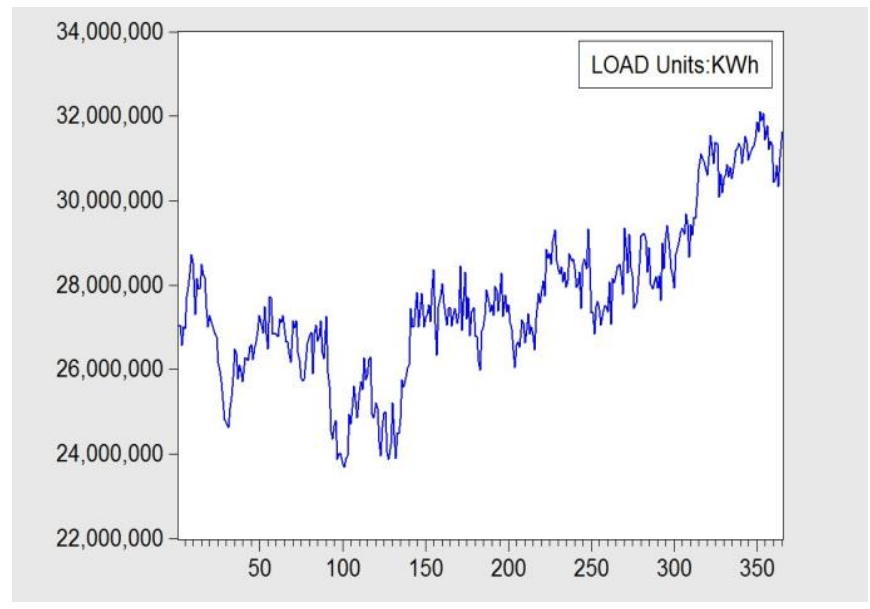

Figure 1. The year 2014 in an area of SiChuan Province load

Using the Eviews software to research the power load for the year of correlation analysis, since the rapid decay of the correlation coefficient is 0 .

Application of the above method to get daily load forecasting ARMA model:

$$
\begin{aligned}
& \left(1-\phi_{1} B_{1}-\phi_{2} B_{2}-\phi_{3} B_{3}-\phi_{4} B_{4}-\phi_{5} B_{5}-\phi_{6} B_{6}-\phi_{7} B_{7}-\phi_{8} B_{8}-\phi_{9} B_{9}\right. \\
& \left.-\phi_{10} B_{10}-\phi_{11} B_{11}\right) \Delta_{T} L(t)=e_{t}
\end{aligned}
$$

In formula, $\mathrm{L}(\mathrm{t})$ is $\mathrm{t}$ load for the first time, $\Phi_{1}, \cdots, \Phi_{11}$ is autoregressive coefficient, $\mathrm{e}_{\mathrm{t}}$ is random noise, $\mathrm{T}$ is number of hours $(\mathrm{T}=24$ or 48 or 96$)$, then the first time the relative error of $\mathrm{t}$ :.

$$
\Delta L(t)=\frac{L^{\prime}(t)-L(t)}{L(t)} \times 100 \%
$$

Try AR (7), MA (1), we use static prediction, the actual forecasting results shown in Table 1.

Null Hypothesis: LOAD has a unit root

Exogenous: Constant

Lag Length: 2 (Automatic based on SIC, MAXLAG=19)

\begin{tabular}{lccc}
\hline \hline & t-Statistic & Prob. $^{*}$ \\
\hline \hline Augmented Dickey-Fuller test statistic & -1.097074 & 0.6693 \\
\hline \multicolumn{1}{l}{ Test critical values: $\quad 1 \%$ level } & -3.436511 & \\
& $5 \%$ level & -2.268307 & \\
& $10 \%$ level & -2.574825 & \\
\hline \hline
\end{tabular}

*MacKinnon (1996) one-sided p-values.

Augmented Dickey-Fuller Test Equation

Dependent Variable: D(LOAD)

Method: Least Squares

Date: 05/03/16 Time: 11:36

Sample (adjusted): 4365

Included observations: 362 after adjustments

\begin{tabular}{lrlll}
\hline \hline \multicolumn{1}{c}{ Variable } & Coefficient & Std. Error & t-Statistic & Prob. \\
\hline \hline LOAD $(-1)$ & -0.016271 & 0.014526 & -1.164074 & 0.2452 \\
D(LOAD $(-1))$ & -0.249623 & 0.052810 & -5.090397 & 0.0000 \\
D(LOAD(-2)) & -0.174418 & 0.052496 & -3.322481 & 0.0010 \\
$\quad$ C & 467505.9 & 386404.1 & 1.209889 & 0.2397 \\
\hline \hline R-squared & 0.090397 & Mean dependent var & 13750.55 \\
Adjusted R-squared & 0.082401 & S.D. dependent var & 508402.1 \\
S.E. of regression & 487005.5 & Akaike info criterion & 29.04580 \\
Sum squared resid & $8.49 E+13$ & Schwarz criterion & 29.08393 \\
Log likelihood & -5252.408 & Hannan-Quinn criter. & 29.03962 \\
F-statistic & 11.80595 & Durbin-Watson stat & 1.961060 \\
Prob(F-statistic) & 0.000000 & & & \\
\hline \hline
\end{tabular}

Figure 2. Sequence analysis of stationary 
Table 1. ARMA daily load forecasting model (load units: $10^{6} \mathrm{KW} \cdot \mathrm{h}$ )

\begin{tabular}{|c|c|c|c|c|c|}
\hline \multicolumn{2}{|c|}{ System data } & \multicolumn{2}{|c|}{$\begin{array}{l}\text { Weighted least } \\
\text { squares }\end{array}$} & \multicolumn{2}{|c|}{$\begin{array}{l}\text { Improved recur- } \\
\text { sive least squares }\end{array}$} \\
\hline $\begin{array}{l}\text { Fore- } \\
\text { cast Date }\end{array}$ & $\begin{array}{l}\text { Real } \\
\text { load }\end{array}$ & $\begin{array}{l}\text { Predic- } \\
\text { tive value }\end{array}$ & $\begin{array}{l}\text { Pre- } \\
\text { diction } \\
\text { error } \%\end{array}$ & $\begin{array}{l}\text { Predic- } \\
\text { tive value }\end{array}$ & $\begin{array}{l}\text { Pre- } \\
\text { diction } \\
\text { error } \%\end{array}$ \\
\hline $\begin{array}{l}\text { 2015- } \\
01-01\end{array}$ & $\begin{array}{l}31.52 \\
3123\end{array}$ & 31.03451 & 1.55 & $\begin{array}{l}31.143 \\
52\end{array}$ & 1.20 \\
\hline $\begin{array}{l}2015- \\
01-02\end{array}$ & $\begin{array}{l}31.55 \\
6034\end{array}$ & 30.86182 & 2.20 & $\begin{array}{l}30.975 \\
43\end{array}$ & 1.83 \\
\hline $\begin{array}{l}2015- \\
01-03\end{array}$ & $\begin{array}{l}31.94 \\
3778\end{array}$ & 31.51254 & 1.35 & $\begin{array}{l}31.545 \\
67\end{array}$ & 1.25 \\
\hline $\begin{array}{l}2015- \\
01-04\end{array}$ & $\begin{array}{l}32.37 \\
2821\end{array}$ & 31.47609 & 2.77 & $\begin{array}{l}31.678 \\
43\end{array}$ & 2.14 \\
\hline $\begin{array}{l}2015- \\
01-05\end{array}$ & $\begin{array}{l}33.27 \\
8424\end{array}$ & 32.83915 & 1.32 & $\begin{array}{l}33.087 \\
53\end{array}$ & 0.57 \\
\hline $\begin{array}{l}2015- \\
01-06\end{array}$ & $\begin{array}{l}33.21 \\
8071\end{array}$ & 32.66997 & 1.65 & $\begin{array}{l}32.456 \\
78\end{array}$ & 2.29 \\
\hline $\begin{array}{l}2015- \\
01-07\end{array}$ & $\begin{array}{l}32.44 \\
5526\end{array}$ & 31.66359 & 2.41 & $\begin{array}{l}31.909 \\
86\end{array}$ & 1.65 \\
\hline
\end{tabular}

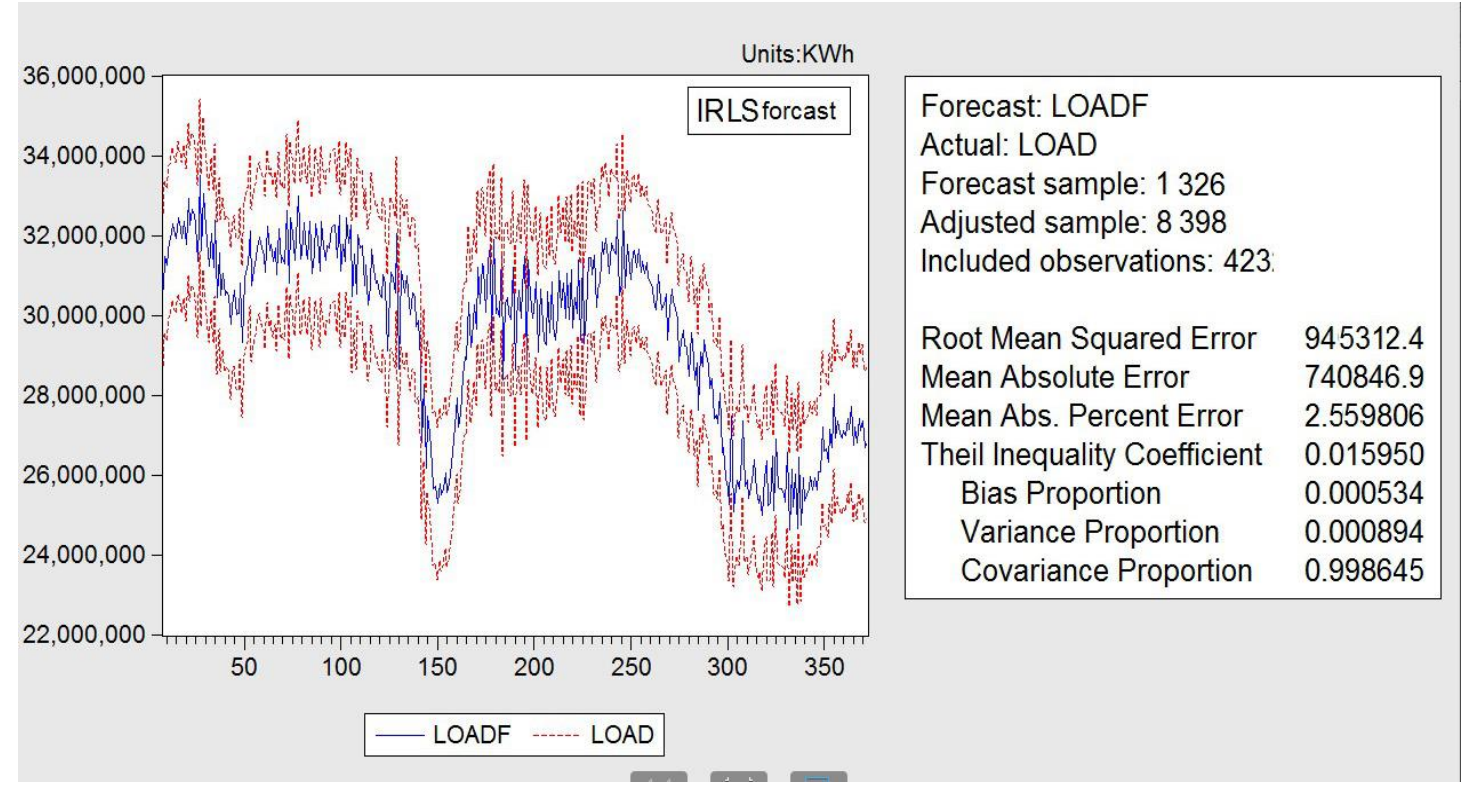

Figure 3. Eviews Daily load forecast

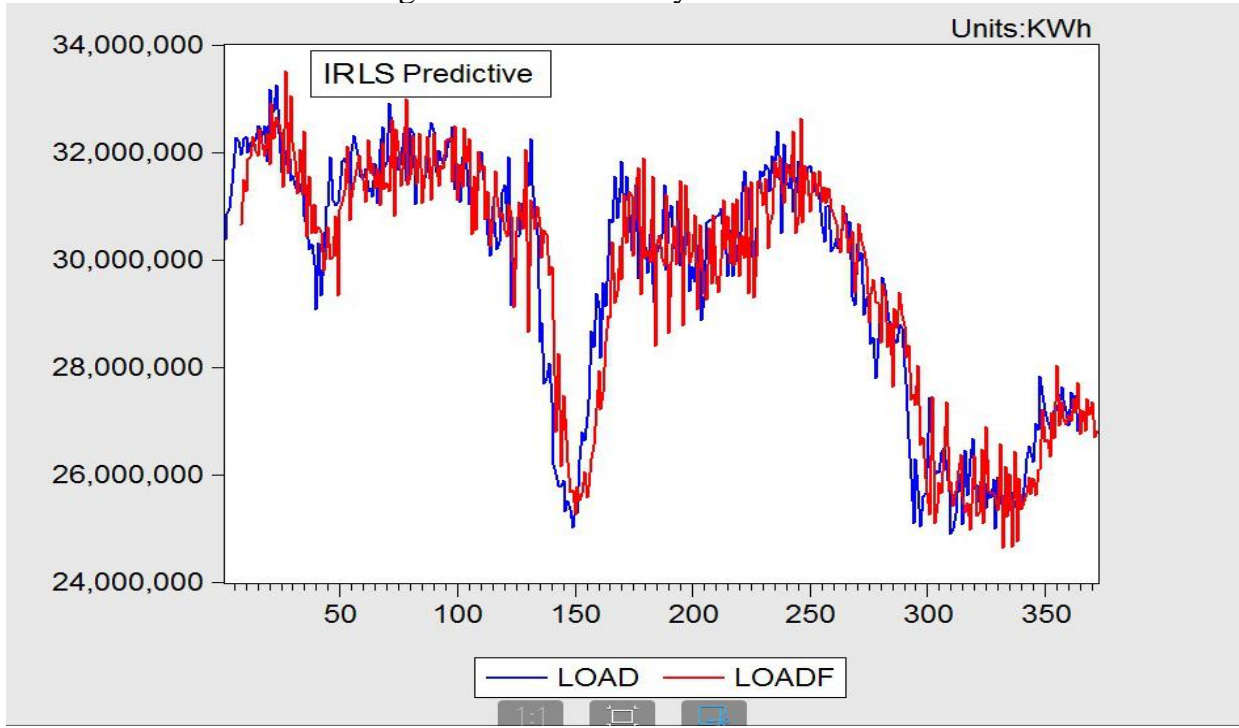

Figure 4. Dynamic relationship between Predictive value and the true value 
Table 2. ARMA daily load forecasting model (load units: $10^{6} \mathrm{KW} \cdot \mathrm{h}$ )

\begin{tabular}{cccccccc}
\hline \hline \multicolumn{2}{c}{ System data } & \multicolumn{3}{c}{ weighted least squares method } & \multicolumn{2}{c}{ improved recursive least squares method } \\
\hline \multirow{2}{*}{ Month } & Load & $\begin{array}{c}\text { Forecast } \\
\text { Date }\end{array}$ & Real load & $\begin{array}{c}\text { Predictive val- } \\
\text { ue }\end{array}$ & $\begin{array}{c}\text { Prediction } \\
\text { error \% }\end{array}$ & $\begin{array}{c}\text { Predictive val- } \\
\text { ue }\end{array}$ & $\begin{array}{c}\text { Prediction } \\
\text { error } \%\end{array}$ \\
\hline $2013-01$ & 993.244983 & $2014-01$ & 838.693646 & 821.0810794 & 2.10 & 827.0987123 & 1.38 \\
$2013-02$ & 900.868487 & $2014-02$ & 741.918461 & 731.0864515 & 1.46 & 736.0564567 & 0.79 \\
$2013-03$ & 986.993165 & $2014-03$ & 826.011498 & 809.4086669 & 2.01 & 813.5678965 & 1.51 \\
$2013-04$ & 939.916142 & $2014-04$ & 749.609450 & 739.4147615 & 1.36 & 741.6789654 & 1.06 \\
$2013-05$ & 877.380040 & $2014-05$ & 797.054905 & 779.3602861 & 2.22 & 781.9876543 & 1.89 \\
$2013-06$ & 893.3137207 & $2014-06$ & 821.964945 & 797.7169791 & 2.95 & 803.8765790 & 2.20 \\
$2013-07$ & 938.170077 & $2014-07$ & 841.749864 & 822.3896171 & 2.30 & 830.6789007 & 1.32 \\
$2013-08$ & 962.977772 & $2014-08$ & 871.067790 & 858.437307 & 1.45 & 860.098765 & 1.26 \\
$2013-09$ & 919.325837 & $2014-09$ & 839.745732 & 822.698936 & 2.03 & 825.908654 & 1.65 \\
$2013-10$ & 851.795386 & $2014-10$ & 883.093083 & 856.6002905 & 3.00 & 859.8754435 & 2.63 \\
$2013-11$ & 772.091566 & $2014-11$ & 910.965867 & 887.9184306 & 2.53 & 891.9876546 & 2.08 \\
$2013-12$ & 830.111797 & $2014-12$ & 969.017688 & 951.7691732 & 1.78 & 956.0987652 & 0.40 \\
\hline \hline
\end{tabular}

\subsection{Results of month load forecasting}

Load forecast during the month, using the following ARMA model:

$\left(1-\phi_{1} B_{1}-\phi_{2} B_{2}-\phi_{3} B_{3}-\phi_{4} B_{4}-\phi_{5} B_{5}\right) \Delta_{T} L_{\text {month }}(n)$

$=e_{n}$

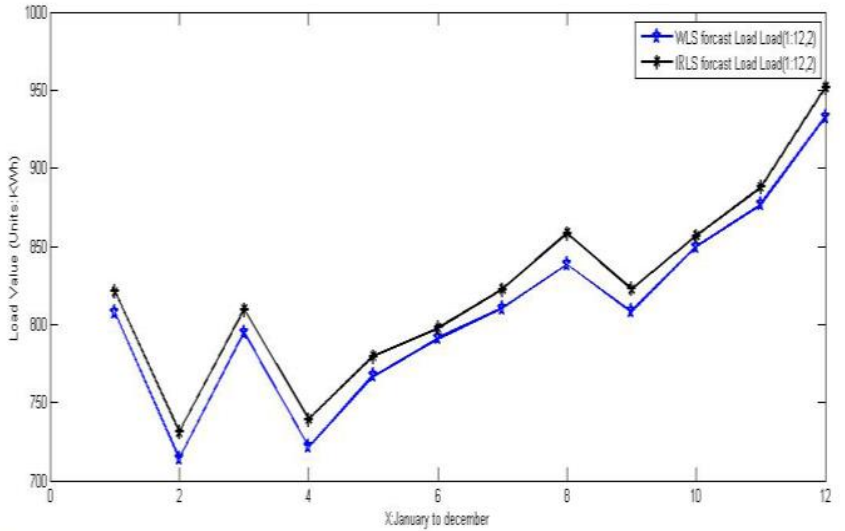

Figure 5. Comparison between Least square method and improved recursive least square method to predict the load values

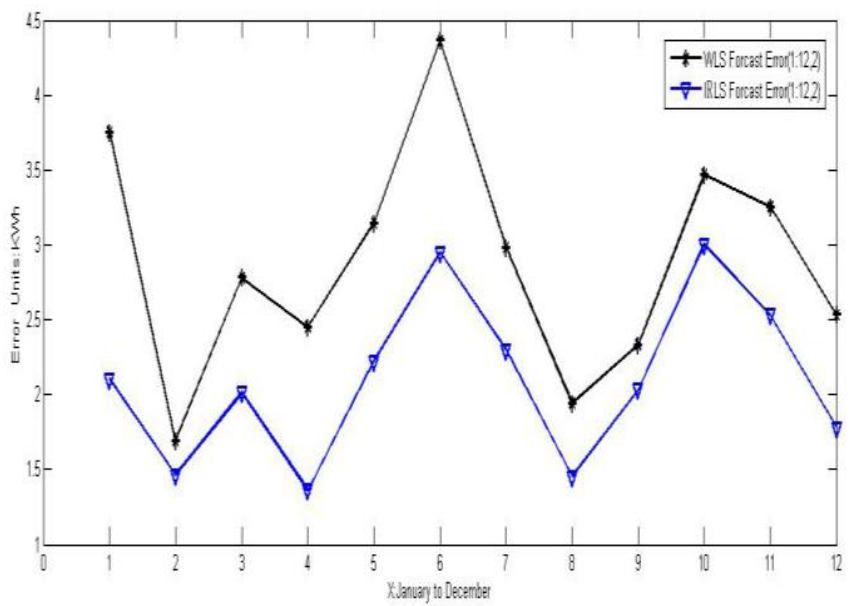

Figure 6. Comparison between Weighted least squares method and Improved recursive least squares method to predict the load values error

In formula, $L_{\text {month }}(n)$ is the electricity consumption of $n$ month, $\Phi_{1}, \ldots, \Phi_{5}$ is Autoregressive coefficient, $e_{n}$ is random noise. As shown the actual prediction. 


\section{Conclusion}

From the above daily and monthly load forecasts can be seen, the use of load forecasting ARMA model is a more effective method. In particular, the improved recursive least square method to estimate the parameters not only improves the forecast accuracy but also robustness the model increased.

\section{Acknowledgement}

Finally, thanks for the support of teachers and students of this writing, for the text data and cited scholars.

\section{References}

[1] Luojun YE,Yaohua LUO,Yong LIU etc. 2002. ARMA Model Based Power System Load Forecasting Methods. Information Technology (6): 74-76.

[2] Lin ZHANG. Xiaochu LUO. \& Ruilin XU. 2006. Time series based on a new algorithm for load forecasting. Power System Technology (30): 595-599.

[3] YANG Qiyu. WANG WeihuA. \& LAN Xinjun. 2002. A Fuzzy Mathematic Method for Long Term Load Forecasting. Journal of Hunan University29 (6): 67-70.

[4] Gu jie. 2002. Fuzzy Methods for Medium and Long-Term Load Forecasting of Power System. Journal of Shanghai Jiaotong University (02): 255-258.

[5] Xie bo. 2007. The Research and Application of the Uncertain Models for Medium and Long Term Load Forecasting. Information Technology, HOHAI UNIVERSITY. NanJing: 10-30. 